\title{
Intervención notarial en conflictos del Agua*
}

\author{
José Antonio Márquez González**
}

RESUMEN: El presente ensayo examina el régimen legal del agua en nuestro país, revisando la Ley de Aguas Nacionales y su Reglamento, la Ley General de Salud, la Ley General de Equilibrio Ecológico y Protección al Ambiente y la Ley Federal de Responsabilidad Ambiental.

Por otra parte, ante la inminente gravedad de los conflictos que resultan por el uso del líquido, se propone la intervención específica del notario como negociador, mediador, conciliador y árbitro, fundamentando su tarea en la larga evolución histórica y en la función social del notario moderno, como experto mediador con atribuciones fedatarias.

Palabras clave: Agua, notario, negociación, mediación, conciliación, arbitraje.
ABSTRACT: This essay examines the legal regime of water in Mexico. It starts with a review of Law on National Waters and its Regulation, the General Health Law, the General Law of Ecological Balance and Environmental Protection, and the Federal Law of Environmental Responsibility. In the near future imminent conflicts will result from the use of the liquid. So, the specific intervention of the latin notary public is proposed as negotiator, mediator, conciliator and arbitrator basing his task on the long historical evolution and on the social function of the modern latin notary public as an expert mediator with public faith.

Keywords: Water, notary public, negotiation, mediation, conciliation, arbitration.

SUMARIO: Introducción. I. El régimen legal del agua. 1. Ley de Aguas Nacionales y su Reglamento; 2. Ley General de Salud; 3. Ley General del Equilibrio Ecológico y Protección al Ambiente; 4. Ley Federal de Responsabilidad Ambiental.

II. La figura del notario latino. 1. Evolución histórica; 2. El notario en la actualidad; 3. La función social del notario moderno; 4. Los conflictos sobre el agua; 5. Las formas alternativas de justicia; 6. Fundamentación legal; 7. El notario como negociador, mediador, conciliador y árbitro; 8. Las ventajas de la intervención del notario.

\section{Introducción}

El presente ensayo hace una revisión meramente normativa del panorama legal del agua bajo una metodología de resumen exegético de las principales disposiciones. Ello aparece

\footnotetext{
* Artículo recibido el 10 de febrero de 2020 y aceptado para su publicación el 12 de mayo de 2020.

** Investigador y docente de la Facultad de Derecho-SEA de la Universidad Veracruzana.
} 
como una mera introducción al propósito esencial de este artículo, cuyo objetivo es proponer de manera directa la intervención calificada de un notario público en la resolución de los eventuales conflictos relacionados con el agua.

Juzgo inútil explorar con más amplitud la evolución histórica del notario de tipo latino. Doy por sentado la disponibilidad cada vez más dramática y escasa del recurso hídrico y el surgimiento de conflictos al respecto. Luego entro inmediatamente al examen de la posibilidad de disminuir la litigiosidad en el tema. Estudio las formas alternativas de justicia, o sea, las figuras de negociación, mediación, conciliación y arbitraje, su fundamentación normativa y la proposición del notario como experto calificado con grandes ventajas para intervenir en el alivio de conflictos.

\section{El régimen legal del agua}

El régimen legal del agua se encuentra enmarcado constitucionalmente en el artículo 27 de la Constitución Política de los Estados Unidos Mexicanos y en la Ley de Aguas Nacionales (LAN). La Ley Federal de Derechos (en sus capítulos correspondientes al agua) y la Ley de Contribución de Mejoras por Obras Públicas Federales de Infraestructura Hidráulica. Otras normas complementarias son el Reglamento de la propia LAN (RLAN), la Ley General del Equilibrio Ecológico y Protección al Ambiente (LGEEPA), la Ley General de Salud (LGS) y la Ley Federal de Responsabilidad Ambiental (LFRA), además de las disposiciones relativas a los códigos civiles, federal y de cada una de las entidades.

En efecto, el artículo 27 de la Constitución en su párrafo 5을 dice que son propiedad de la nación las aguas de los mares territoriales, las aguas interiores, lagunas, esteros, ríos y sus afluentes, lagos y lagunas. Las aguas del subsuelo pueden ser libremente alumbradas y ser apropiadas por el dueño del terreno. Cuando lo exija el interés público, el Ejecutivo Federal reglamentará su extracción y utilización y aun establecerá zonas vedadas.

La propia Constitución menciona que puede haber otras modalidades de propiedad o dominio cuando las aguas sean parte de los terrenos donde corran o en los que se encuentren sus depósitos; si se localizaren en dos o más predios se sujetarán a las disposiciones que dicten las entidades federativas. Igualmente el apartado sexto del mismo artículo 27, dice que el dominio de las aguas de propiedad nacional es inalienable e imprescriptible y solo se podrá explotar, usar o aprovechar este recurso mediante concesión otorgada por el Ejecutivo Federal, de acuerdo a las reglas y condiciones que establezcan las leyes. La Ley de Aguas Nacionales es la normativa que reglamenta el artículo 27 constitucional, en los párrafos quinto y sexto e incluye a las aguas del subsuelo como propiedad nacional.

La Suprema Corte de Justicia de la Nación -SCJN-, ha emitido diversas interpretaciones sobre la propiedad de las aguas subterráneas al grado que en 1973 determinó que las aguas del subsuelo no eran propiedad de la nación (1973, p. 395). A partir de 1988, sustentó una nueva tesis jurisprudencial en el sentido de que sí lo son (1988, p. 13).

Por su parte, el Código Civil Federal (CCF) menciona en algunos puntos este recurso natural, especialmente en el artículo 750, fracciones IX y XI, que se refiere a los manantiales, estanques, aljibes y corrientes de agua, así como a los acueductos y a las cañerías de 
cualquier especie que sirvan para conducir los líquidos o gases a una finca o para extraerlos de ella. También a los diques y construcciones que, aun cuando sean flotantes, estén destinados por su objeto y condiciones a permanecer en un punto fijo de un río, lago o costa. El código los conceptúa a todos como bienes de naturaleza inmueble.

En términos de los artículos 768 y 770 de dicho código, al igual que el artículo 27 para las aguas de propiedad nacional, se establece que los bienes de uso común son inalienables e imprescriptibles y que los bienes destinados a un servicio público y los bienes propios, pertenecen en pleno dominio a la federación, a los estados o a los municipios y que los primeros son también inalienables e imprescriptibles.

EI CCF añade que las servidumbres de acuerdo al artículo 29 bis 6 de la LAN, "se aplican sobre aquellas áreas indispensables para el uso, reúso, aprovechamiento, conservación y preservación del agua, ecosistemas vitales, defensa y protección de las riberas, caminos y, en general, para las obras hidráulicas que las requieran"(1992); se establecen por utilidad pública o comunal, para mantener expedita la navegación de los ríos, la construcción o reparación de las vías públicas, y para las demás obras comunales de esta clase, se fijarán por las leyes y reglamentos especiales, y a falta de estos, por las disposiciones del mismo código. En cuanto a la pesca y el buceo de perlas, se especifica que cuando este tipo de actividades se realice en aguas del dominio público, que sean de uso común, se regirán por lo que dispongan las leyes y reglamentos respectivos. A su vez, el derecho de pesca pertenece a los dueños de los predios en que aquéllas se encuentren, con sujeción a las leyes y reglamentos de la materia.

se aplican servidumbres sobre aquellas áreas indispensables para el uso, reúso, aprovechamiento, conservación, y preservación del agua, ecosistemas vitales, defensa y protección de las riberas, caminos y, en general, para las obras hidráulicas que las requieran.

Disposiciones específicas tienen lugar en cuanto al derecho de accesión es decir, a las incorporaciones naturales o artificiales que sufre un bien, ya sea por causa de acrecentamiento por aluvión, disminución natural de las aguas crecidas extraordinarias, arrancamiento de porciones, árboles arrastrados por la corriente de las aguas, cauces abandonados de ríos federales, islas en los mares adyacentes, ríos que pertenecen a la Federación, divisiones fluviales limítrofes, brazos o ramales, etcétera (artículos 908 a 915).

Un capítulo especial se conforma bajo el título "Del dominio de las aguas", que comprende los artículos 933 a 937. El artículo 933 dice que:

El dueño del predio en que exista una fuente natural, o que haya perforado un pozo brotante, hecho obras de captación de aguas subterráneas o construido aljibe o presas para captar las aguas pluviales, tiene derecho de disponer de esas aguas; pero si éstas pasan de una finca a otra, su aprovechamiento se considerará de utilidad pública y quedará sujeto a las disposiciones especiales que sobre el particular se dicten.

El dominio del dueño de un predio sobre las aguas de que trata este artículo, no perjudica los derechos que legítimamente hayan podido adquirir a su aprovechamiento de los predios inferiores.

El artículo 934, por su parte, releva de la obligación de indemnizar a quien perfore pozos o haga obras de captación de aguas subterráneas en su propiedad, aunque por esto disminuya el agua del abierto en fundo ajeno. Tampoco podrá desviarse el curso de las 
aguas si se causan daños a un tercero (artículo 935) y se previene también el pago a prorrata de la recuperación de los gastos de los predios vecinos, mediante indemnización fijada por peritos, a aquél propietario de un predio cuyo acceso al recurso hídrico resulte demasiado oneroso (artículo 937).

En capítulo por separado se regulan las servidumbres legales de desagüe (artículo 1071) y acueducto (artículo 1078).

La primera de ellas establece la obligación de indemnización en favor de los predios sirvientes y a cargo de los predios inferiores que reciban las aguas de los superiores, a consecuencia de mejoras agrícolas o industriales. Se trata también de las aguas insalubres y de su limpieza o recuperación, siempre a costa del dueño del predio dominante (artículo 1077).

En lo que se refiere a la servidumbre legal de acueducto, se establece asimismo el derecho a hacer pasar el agua por los fundos intermedios, con la obligación de indemnizar a los dueños y construyendo además los canales necesarios. En estos casos se debe previamente justificar que el solicitante puede disponer del agua que pretende conducir, acreditar que el paso que solicita es el más conveniente y el menos oneroso, pagar el valor del terreno que ha de ocupar el canal (según estimación de peritos, y un diez por ciento más) y resarcir los daños inmediatos (artículo 1086).

Esta servidumbre legal de acueducto involucra, desde luego, un derecho de tránsito de personas y animales, así como de los materiales correspondientes y el necesario mantenimiento de las instalaciones. Son aplicables a esta servidumbre genérica los casos de los terrenos pantanosos o aguas estancadas a las cuales se desee desecar o dar salida. Disposiciones especiales, en cambio, rigen en el caso de servidumbres de estribos de presa para el mejor aprovechamiento del agua.

La Ley de Aguas Nacionales, por su parte, menciona dos tipos de servidumbre: las servidumbres naturales y las forzosas o legales. Las naturales se refieren a los cauces de propiedad nacional en los cuales no existan obras de infraestructura; las forzosas o legales a aquellas sobre cuyos fundos se realice la construcción de obras hidráulicas como embalses, derivaciones, tomas directas y otras captaciones, obras de conducción, tratamiento, drenajes, obras de protección de riberas y obras complementarias, incluyendo caminos de paso y vigilancia (1992).

\section{Ley de Aguas Nacionales y su Reglamento}

Por otra parte, siguiendo la regulación constitucional, se dictó la Ley de Aguas Nacionales (LAN) publicada en el Diario Oficial de la Federación el 1 de diciembre de 1992 por el presidente Carlos Salinas de Gortari. Esta ley incorpora reformas recientes del 6 de enero de 2020. Va acompañada de su reglamento de fecha 12 de enero de 1994 y con reformas sustanciales al 2014. En 2004 se reformaron 114 artículos (de los 124 de los que consta) y se adicionaron 66 que se han denominado como bis, lo que en realidad hace un total de 190 artículos.

La LAN consta de un total de 124 artículos, con algunos denominados bis, en virtud de las reformas necesarias. Está dividida en diez capítulos, que se refieren, por su orden, a la 
administración del agua y a las autoridades respectivas (Secretaría del Medio Ambiente y Recursos Naturales, la Comisión Nacional del Agua, los Consejos de Cuenca, el Consejo Consultivo del Agua, el Servicio Meteorológico Nacional, el Instituto Mexicano de Tecnología del Agua y la Procuraduría Federal de Protección al Ambiente). Además, se examinan la política y programación hídricas, los derechos de explotación, uso o aprovechamiento de aguas nacionales, las concesiones y asignaciones, y los casos de suspensión, extinción, revocación, restricciones y servidumbres. Incluye también el Registro Público de Derechos de Agua, la transmisión de títulos, los usos del agua (urbano y agrícola), la cultura del agua, la prevención y el control de la contaminación de las aguas, la responsabilidad por daño ambiental, la inversión en infraestructura hidráulica, el sistema financiero del agua y el régimen de infracciones, sanciones y recursos.

El Reglamento de la Ley de Aguas Nacionales (RLAN) sigue, desde luego, la misma estructura y añade un título undécimo que trata de la conciliación y del arbitraje.

La LAN es muy prolija y compleja desde el punto de vista técnico. Desde el principio, contiene un largo capítulo de definiciones; en el artículo tercero (cfr. artículo 2, I-XXV), con un total de 71 conceptos, desde "Aguas Nacionales" hasta "Zonas Marinas Mexicanas". Juzgo innecesario consignar por extenso cada uno de los conceptos, excepto en lo que resulte conveniente en el presente trabajo.

La autoridad máxima en esta materia se ejerce por el Ejecutivo Federal, quien tiene a su cargo una serie de acciones de coordinación que puede ejercitar en forma directa o a través de la denominada Comisión Nacional del Agua (CONAGUA) y de los Consejos de Cuenca (CC).

La competencia directa del Ejecutivo Federal se encuentra regulada en el artículo 6 de la LAN. Puede resumirse en sus facultades de reglamentación en lo relativo a la extracción y explotación, uso o aprovechamiento de las aguas, el establecimiento, modificación o supresión de zonas reglamentadas, sustentabilidad de los ecosistemas vitales en áreas determinadas en acuíferos, cuencas hidrológicas, o regiones hidrológicas, expedición de decretos para el establecimiento de zonas de veda, declaratorias de zonas de reserva, declaratorias de rescate, pago de indemnizaciones, decretos de expropiación, de ocupación temporal, total o parcial de los bienes, emisión de políticas y lineamientos, cumplimiento de acuerdos y convenios internacionales, nombrar al director general de ciertas autoridades y establecer distritos de riego o de temporal tecnificado.

La CONAGUA es un órgano administrativo desconcentrado de la Secretaría de Medio Ambiente y Recursos Naturales (SEMARNAT), con autonomía técnica, ejecutiva, administrativa, presupuestal y de gestión (artículo 3, XII, LAN), que se integra en dos modalidades, a nivel nacional y a nivel regional hidrológico-administrativo, en este último caso a través de los Organismos de Cuenca (OC) que tienen a su cargo la materia operativa, ejecutiva, administrativa y jurídica. Es una larga enumeración que comprende un total de 54 fracciones en el artículo 9 de la LAN.

Los CC son órganos colegiados de integración mixta, instancia, coordinación, concertación, apoyo, consulta y asesoría, entre la Comisión (incluyendo el OC que corresponda), las dependencias y entidades de las instancias federal, estatal o municipal, 
los representantes de los usuarios de agua y de las organizaciones de la sociedad, de la respectiva cuenca hidrológica o región hidrológica (artículo 3, XV, LAN). Ya se ve pues que se trata de organismos con vocación local y cuya particularidad es que en un ámbito geográficamente limitado se logre la concentración de los tres órdenes de gobierno, además de los particulares. En los artículos 18 al 21 del RLAN se reglamentan la organización y la participación de los usuarios.

Los OC corresponden a la autoridad del agua y, como ya dije, los CC son de composición mixta. Los primeros disponen de una gran autonomía como unidades de tipo técnico, administrativo y jurídico, siempre reducidas a cada unidad o, como dice la ley, con un "perfil de unidades regionales especializadas".

Cada OC posee un director general subordinado a su vez al Director General de la CONAGUA, pero está auxiliado por un CC integrado por las siguientes autoridades: titulares de las Secretarías de Hacienda y Crédito Público (SHCP), de Desarrollo Social (SEDESOL), de Energía (SENER), de Economía (SE), de Medio Ambiente y Recursos Naturales (SEMARNAT), de Salud (SSA), de Agricultura, Ganadería, Desarrollo Rural, Pesca y Alimentación (SAGARPA), y Comisión Nacional Forestal (CONAFOR) (artículo 12 bis 2, VII, LAN). Intervienen asimismo el Ejecutivo del Estado correspondiente y un representante de la presidencia municipal. Nuevamente las atribuciones de los $\mathrm{OC}$ se encuentran reguladas en un total de 33 fracciones previstas en el artículo 12 bis 6 .

Es necesario aclarar que los CC, como órganos de integración mixta y colegiada, no se encuentran jerárquicamente subordinados ni a la CONAGUA ni a los OC. Los CC disponen de un presidente, de un secretario técnico y de vocales que representan a los tres órdenes de gobierno, a los usuarios del agua y a las organizaciones de la sociedad (artículo 3, XV, LAN), siempre delimitados a cada cuenca hidrológica o bien a un grupo de cuencas hidrológicas. Para su organización operativa cuenta con cuatro órganos, a saber: la Asamblea General de Usuarios, el Comité Directivo del Consejo de Cuenca, la Comisión de Operación y Vigilancia del Consejo de Cuenca y la Gerencia Operativa (artículo 13 bis 1, LAN). Las atribuciones de los CC están definidas en el artículo 13 bis 3.

Un punto importante de la LAN se refiere a la organización y participación de los usuarios del agua y de la sociedad. De hecho, el capítulo diez de la ley se dedica especialmente a este rubro, promoviendo la participación de las organizaciones ciudadanas o no gubernamentales, así como de los colegios de profesionales y los grupos académicos, además de ejidos, comunidades, centros educativos y personas interesadas en general.

Otras organizaciones importantes son el Consejo Consultivo del Agua (CCA), el Servicio Meteorológico Nacional (SMN), el Instituto Mexicano de Tecnología del Agua (IMTA) y la Procuraduría Federal de Protección al Ambiente (PROFEPA).

Tal vez uno de los títulos más destacados de la ley se refiere a los derechos de explotación, uso o aprovechamiento de las aguas nacionales, de conformidad con lo previsto en el artículo 27 de la Constitución. Algunos puntos importantes de este tema son los siguientes: la explotación uso y aprovechamiento totalmente libre de aguas superficiales para uso doméstico (a menos que haya necesidad de desvíos o alteraciones), la necesidad de concesión para la desalinización de las aguas marinas, alumbramiento libre de aguas en 
el subsuelo (sin perjuicio de las contribuciones fiscales) e inscripción en el Registro Público de Derechos de Agua (REPDA).

La forma de explotar, usar o aprovechar las aguas nacionales se realiza mediante concesión o asignación del Ejecutivo Federal, de la Comisión y los OC. El documento que incorpora estas concesiones o asignaciones se llama título, ya se trate de concesión, asignación o de permisos de descarga. El beneficiario recibe el nombre de concesionario, con los derechos y obligaciones que marca la ley.

El trámite inicia con la solicitud de concesión o asignación, la cual debe contener los siguientes datos: nombre y domicilio del solicitante; la cuenca hidrológica, acuífero en su caso, región hidrológica, municipio y localidad a que se refiere la solicitud; el punto de extracción de las aguas que se soliciten; el volumen de extracción y consumo requeridos; el uso inicial; el punto de descarga de las aguas residuales; el proyecto de las obras a realizar, incluyendo tratamiento de las aguas y costo económico y ambiental y la duración de la concesión o asignación. Al propio tiempo el beneficiario debe obligarse expresamente a pagar las contribuciones fiscales (artículo 21, LAN).

El solicitante debe adjuntar los documentos relativos que se refieran a la propiedad o posesión del inmueble, el documento que acredite la constitución de las servidumbres, la manifestación de impacto ambiental, el proyecto de las obras a realizar, la memoria técnica con los planos correspondientes, la documentación técnica que soporte la solicitud en términos del volumen de consumo requerido, el uso inicial que se le dará al agua, las condiciones de cantidad y calidad de la descarga de aguas residuales y un croquis que indique la ubicación del predio (artículo 21 bis, LAN).

Asimismo, como producto de las reformas de 2004, es obligación ineludible de la Autoridad del Agua contestar toda solicitud en 60 días, una vez que se haya integrado el expediente. Esta concesión o asignación no puede ser menor de cinco años, ni mayor de 30 años, en términos del artículo 24 de la LAN.

Es importante aclarar que los usos domésticos y público-urbanos siempre son preferentes sobre cualquier otro uso, por ejemplo agrícolas, comerciales o industriales. Los derechos que se hayan concedido se suponen asignados sin perjuicio de terceros; tampoco garantizan un caudal siempre constante en el volumen del agua. Estos derechos (y las obligaciones relativas) de los concesionarios o asignatarios se encuentran previstos en los artículos 28 y 29 de la ley; los derechos están restringidos a apenas siete fracciones que se refieren a la explotación, uso o aprovechamiento, confección de trabajos u obras, servidumbres, transmisión de derechos, renuncia, expedición de títulos y prórroga de los plazos.

Al propio tiempo las obligaciones se encuentran previstas en diecisiete fracciones del artículo 29 y consisten básicamente en las siguientes: ejecución efectiva de las obras y trabajos, instalación y conservación de medidores de agua, pago de los derechos, trabajos de seguridad hidráulica y de equilibrio ambiental, facilidades de inspección, información y documentación por la autoridad, uso eficiente del agua, limitación a los volúmenes autorizados, aviso de desperfectos, prevención de la contaminación, limpieza de los cauces, 
presentación de informes, calidad del agua, tratamiento de aguas residuales y responsabilidad por costos ambientales.

Las concesiones, asignaciones y permisos pueden ser objeto de suspensión por el incumplimiento de estas obligaciones y asimismo pueden extinguirse por el término de la vigencia, renuncia del titular, cegamiento del aprovechamiento, muerte del beneficiario y nulidad del trámite o título. Ahora bien, estas causas de suspensión o de extinción pueden anularse por ciertas razones excepcionales, a saber, caso fortuito o fuerza mayor, mandamiento judicial o resolución administrativa, pago de cuotas por garantía, transmisión temporal de los derechos, inversiones económicas para mejorar la eficiencia, declaratoria de rescate, etcétera.

Otra figura jurídica que concurre en estos casos es la revocación, la cual tiene lugar mediante casos específicos previstos en el artículo 29 bis 4, que se refiere al exceso en la disposición del agua, incumplimiento de las Normas Oficiales Mexicanas (NOM), descargas ilegales, no obtención de permisos, falta de pago de contribuciones, aprovechamientos o tarifas, daños al ecosistema, residuos peligrosos o dañinos, transmisión de derechos sin permiso, uso distinto de las aguas al permitido, etcétera.

EI REPDA está a cargo de la CONAGUA en el ámbito nacional y de los OC en el ámbito local. En este registro se inscriben los títulos de concesión y asignación de aguas nacionales, y sus bienes públicos inherentes, así como los permisos de descargas de aguas residuales, las prórrogas, las modificaciones y rectificaciones, la transmisión de los títulos de concesión, la suspensión, revocación o terminación de los títulos enunciados, las sentencias definitivas de los tribunales judiciales y administrativos, las resoluciones que amplíen o doten de agua, los padrones de usuarios de los distritos de riego, los estudios de disponibilidad de agua y las zonas reglamentadas, de veda y las declaratorias de reserva de aguas nacionales. Además, los actos que efectúe la autoridad se inscribirán de oficio, pero los relativos a la transmisión total o parcial de los títulos, así como a los cambios que se efectúen en sus características o titularidad, se inscribirán a petición de parte interesada, por orden de presentación y una vez que se satisfagan los requisitos que establezcan los reglamentos (artículo 30 LAN; artículos 54-63, RLAN).

Este REPDA funciona por cada región hidrológico-administrativa. La inscripción de los actos es oficiosa o a solicitud de parte interesada por riguroso orden cronológico y con el pago correspondiente de los derechos, según el artículo 59, del RLAN. Es importante precisar que la inscripción en el REPDA surte efectos constitutivos en términos de lo dispuesto en los artículos 31 párrafo I y 34 párrafo III de la LAN, que es prueba contundente de la existencia, titularidad y la situación legal del derecho al recurso. El registro es público, pero la expedición de los certificados tiene un costo. Por cierto que el trámite de las solicitudes relacionadas con las constancias del REPDA puede efectuarse por vía remota en término de lo dispuesto en el artículo 31, párrafo final.

Como ya he dicho, los títulos para la explotación, uso o aprovechamiento de las aguas pueden transmitirse, siempre sujetos a los siguientes requisitos: elaboración de una solicitud por escrito, autorización previa de la autoridad, publicación en el Diario Oficial de 
la Federación, inscripción en el REPDA en el plazo de 15 días hábiles e incluso aviso final del uso efectivo.

La transmisión de los derechos tiene lugar conjuntamente con la transmisión de la propiedad del inmueble. Sin embargo, pueden hacerse también en forma separada, de conformidad con los casos excepcionales previstos en el reglamento (artículo 72, RLAN, en relación con el artículo 35, LAN).

En términos del artículo 65 del RLAN:

Artículo 65. Para efectos del artículo 20 de la "Ley", cuando un asignatario transmita a un particular sus derechos de explotación, uso o aprovechamiento de aguas, o viceversa, no se requerirá sustituir el título, bastando la inscripción de la transmisión en el "Registro" y la anotación de la inscripción correspondiente en el título original.

En otros dos casos, cuando solo se cambie de titular, sin modificar las características del título y cuando se trate de cuencas, entidades federativas o localidades en que se haya autorizado la transmisión de los títulos por la simple inscripción en el Registro, bastará la simple presentación de un aviso por escrito (artículo 66, RLAN). Este aviso debe ser firmado por el concesionario o asignatario y por el adquirente, bajo protesta de decir verdad. Solamente en los casos del simple aviso, puede efectuarse (la ley dice "se podrá efectuar...") por notario, corredor público o fedatario (artículo 68, RLAN). También se previene la transmisión de los títulos por vía sucesoria o adjudicación judicial, con los requisitos que menciona el artículo 71 del RLAN, y un largo plazo de 60 días hábiles para que la Comisión autorice, pero con la novedad de que no habiendo resolución, se presume la respuesta positiva ficta de la autoridad.

Los usos del agua son muy diversos. La LAN los clasifica en los siguientes: uso público urbano, agrícola, para generación de energía eléctrica y otras actividades productivas.

a. El primero, uso público urbano, se refiere a la explotación, uso o aprovechamiento de las aguas por las autoridades estatales o municipales de agua potable y alcantarillado, incluyendo a la Ciudad de México, aun cuando se previene en la ley su concesión o a su administración por entidades paraestatales o paramunicipales o a particulares. Incluye asimismo el tratamiento de las aguas residuales antes de su descarga en los denominados "cuerpos receptores". También se prevé el establecimiento de sistemas regionales donde puedan unirse entidades municipales o estatales, y obras de captación o almacenamiento, conducción, tratamiento o potabilización con fondos federales u obtenidos mediante garantía, siempre que las obras se localicen en un área regional, exista participación de los diversos órganos de gobierno, haya financiamiento, se garantice la recuperación de la inversión, se administre eficientemente el recurso, se mantenga y rehabilite la infraestructura hidráulica y participen todos los beneficiarios en el proceso.

b. El uso agrícola se refiere a la explotación uso o aprovechamiento de aguas por parte de los ejidatarios, comuneros y pequeños propietarios, ejidos, comunidades y sociedades, titulares o poseedores de tierras agrícolas, ganaderas o forestales. Un caso especial se conforma con la hipótesis del otorgamiento de concesiones a personas morales, porque en este caso se debe elaborar un reglamento que precisa diversas características del aprovechamiento del recurso en términos del artículo 51 y se exige llevar un padrón de los 
derechos de explotación, uso o aprovechamiento. El padrón es público, tiene efectos probatorios y debe actualizarse constantemente.

Los artículos 56, 56 bis y 57 son importantes porque previenen la transmisión de la titularidad de la tierra con los derechos relativos al agua y exigen su inscripción en el REPDA. c. El uso para la generación de energía eléctrica y enfriamiento de plantas previene su concesión a la Comisión Federal de Electricidad (CFE), y también a particulares para su uso o aprovechamiento "en pequeña escala". Los proyectos de la CFE, una vez aprobados por la Comisión, formarán parte de los planes generales sobre aprovechamiento de los recursos hídricos del país. En el segundo caso, que se refiere a su aprovechamiento por particulares "en pequeña escala", no se requiere concesión.

d. El uso en otras actividades productivas comprende la explotación, el uso o aprovechamiento de aguas en actividades industriales de acuacultura, turismo y otras actividades productivas.

Un capítulo especial, el $\mathrm{V}$ bis, se refiere a la cultura del agua, para lo cual se busca la coordinación con las autoridades educativas e incorporar en los programas de estudio ciertos conceptos sobre la cultura del agua, en particular sobre la disponibilidad del recurso; su valor económico, social y ambiental; su uso eficiente; las necesidades y ventajas del tratamiento y reúso de las aguas residuales; la conservación del agua y su entorno; el pago por la prestación de servicios de agua en los medios rural y urbano y los derechos por extracción, descarga y servicios ambientales; la instrumentación de campañas permanentes de difusión e información a la población sobre la escasez de agua, costos para proveerla, su valor económico, social y ambiental y la cultura de pago por dicho servicio.

Se proporcionará información sobre los efectos adversos de la contaminación, así como la necesidad de reusar las aguas residuales y fomentar el uso racional y conservación del líquido como tema de seguridad nacional (artículo 84 bis), así como el uso de medios masivos de comunicación, especialmente en programas dirigidos a la población infantil, en términos de la Ley Federal de Radio y Televisión.

En cuanto a la prevención y control de la contaminación de las aguas, se establecen facultades específicas de la autoridad del agua en el artículo 86, especialmente para la preservación de los humedales, contaminación por basura, vertidos, infiltraciones, control de descargas, todo ello con sujeción a las NOM, con facultades preventivas de suspensión de actividades, revocación del permiso de descargas y responsabilidad por daño ambiental.

Se establecen normas complementarias en lo relativo a las necesarias inversiones en infraestructura hidráulica, participación de inversión privada y social en las obras hidráulicas federales, recuperación de la inversión, cobro por la explotación, uso o aprovechamiento en lo que se denomina ahora "Sistema financiero del agua", a cargo de la Comisión y bajo la supervisión de la SHCP.

Los bienes nacionales que quedan bajo la administración y supervisión de la Comisión son los siguientes: las playas y zonas federales, los vasos de lagos, lagunas, esteros o depósitos naturales, los cauces de las corrientes de aguas nacionales, las riberas o zonas federales, los terrenos de los cauces y vasos de lagos, las islas, las obras de infraestructura hidráulica y los materiales pétreos. Se establece además la necesidad de las 
correspondientes declaratorias de aguas nacionales, por conducto del Ejecutivo Federal, así como el derecho de accesión cuando ocurran cambios en el curso de una corriente o en los niveles de lagos, lagunas, esteros o descubrimiento de nuevas tierras, terrenos ganados por medios artificiales, desecamientos, encausamiento o limitación.

La LAN establece diversas medidas de apremio, de seguridad, infracciones, sanciones y recursos en un poscapítulo añadido como producto de las reformas recientes del 8 de junio de 2012 y del 3 de enero de 2020. En los términos de este capítulo, se establecen medidas de clausura temporal y suspensión de actividades, así como adopción de medidas urgentes para proteger la vida y los bienes de los ciudadanos, con una numeración taxativa de las faltas o infracciones susceptibles de penalización en un total de 24 fracciones del artículo 119. Las multas se indexan a la UMA vigente en la Ciudad de México, independientemente de las multas aplicables en otros ordenamientos. Si es el caso, además de la comisión de un delito, la propia Comisión formulará la denuncia ante el Ministerio Público.

La ley previene los recursos de revisión y denuncia popular contra sus actos o resoluciones definitivas. En efecto, el artículo 124 bis dice lo siguiente:

Artículo 124 bis. Toda persona, grupos sociales, organizaciones ciudadanas o no gubernamentales, asociaciones y sociedades, podrán recurrir a la denuncia popular en los términos del Capítulo VII de la Ley General de Equilibrio Ecológico y Protección al Ambiente, cuando se cometan actos que produzcan o puedan producir desequilibrios o daños a los recursos hídricos o sus bienes inherentes.

Esta ley ha sufrido reformas en años recientes. En 2013 se estableció que la Autoridad del Agua deberá intervenir para la reparación del daño ambiental, incluso en ecosistemas vitales (artículo 96 bis). En 2014 hubo modificaciones en cuanto a la concesiones de agua por alteración de los puntos de extracción o modificación de los pozos (artículo 81). Una reforma de 24 de marzo de 2016 atañe a los denominados "aprovechamiento de paso" y "uso en acuacultura" (artículo 3 XVII, 57). El Reglamento de esta ley se reformó asimismo el 25 de agosto de 2014 para posibilitar la realización de visitas de inspección en términos de la Ley Federal del Procedimiento Administrativo (artículos 11 y 153).

\section{Ley General de Salud}

Complementando las disposiciones de la LAN, la LGS contiene algunas pocas disposiciones aisladas que se refieren a este recurso. Estas disposiciones tratan principalmente de las acciones sanitarias, educativas y laborales relacionadas con el acceso al agua potable y los medios sanitarios de eliminación de excreta (artículo 65, IV), emisión de normas técnicas para el tratamiento del agua para uso y consumo humano (artículo 118, II), criterios sanitarios para fijar las condiciones particulares de descarga, tratamiento y uso de aguas residuales y NOM Ecológicas (artículo 118, III), facultades de la SSA y gobiernos locales para vigilar y certificar la calidad del agua para uso y consumo humano (artículo 119, II), descargas peligrosas de aguas residuales (artículo 122) y delitos relacionados con la contaminación de cuerpos de agua superficiales o subterráneos (artículo 457).

Esta ley tuvo reformas el 8 de diciembre de 2017 en cuanto a la competencia de la Secretaría de Salud para la determinación y evaluación de riesgos sanitarios a consecuencia del cambio climático. 


\section{Ley General del Equilibrio Ecológico y Protección al Ambiente}

La LGEEPA de 1988 trata diversos temas relacionados con el aprovechamiento sustentable, la preservación y la restauración de los recursos naturales en general y prevención y control de la contaminación (artículo 1, V y Vl; artículo 3, VII), así como el aprovechamiento de aguas nacionales junto con la biodiversidad y fauna (artículo 5, XI; artículo 7, VIII; artículo 8, VII; artículo 11, V). Mención especial merece el establecimiento de bases para los convenios o acuerdos de coordinación de la Federación por conducto de la SEMARNAT con los gobiernos locales (artículo 12) y el diseño, desarrollo y aplicación de instrumentos de mercado consistentes en las concesiones, autorizaciones, licencias y permisos para emisión de contaminantes en el aire, agua o suelo, todo lo cual constituye una actividad prioritaria para efectos del otorgamiento de estímulos fiscales conforme a la Ley de Ingresos de la Federación (artículo 22 bis, III), estableciendo el criterio de aprovechamiento del agua considerando los costos de su tratamiento de manera equitativa y garantizando el otorgamiento de estímulos fiscales y retribuciones económicas a los propietarios, poseedores y titulares de derechos sobre tierras, aguas y bosques en áreas naturales protegidas (artículo 45 bis).

Son criterios a considerar para el aprovechamiento sustentable del agua y de los ecosistemas acuáticos, entre otros, la protección de suelos y áreas boscosas y selváticas, así como el mantenimiento de los caudales de las corrientes de agua y la capacidad de recarga de los acuíferos, responsabilidad que se imputa a los usuarios, en términos del Programa Nacional Hidráulico (artículos 88 y 89). Tal vez los artículos más importantes en el tema del aprovechamiento sustentable son los artículos 90 y 92 que literalmente establecen lo siguiente:

Artículo 90. La secretaría, en coordinación con la Secretaría de Salud, expedirá las normas oficiales mexicanas para el establecimiento y manejo de zonas de protección de ríos, manantiales, depósitos y en general, fuentes de abastecimiento de agua para el servicio de las poblaciones e industrias, y promoverá el establecimiento de reservas de agua para consumo humano.

Artículo 92. Con el propósito de asegurar la disponibilidad del agua y abatir los niveles de desperdicio, las autoridades competentes promoverán el ahorro y uso eficiente del agua, el tratamiento de aguas residuales y su reuso [...]. (1988)

En cuanto a la protección del ambiente, las reformas de los años 1996 y 2001 crearon el registro de emisiones y transferencia de contaminantes al aire, agua, suelo y subsuelo, con base en los reportes y trámites diversos de cada una de las entidades locales (artículo 109 bis). Se establecen asimismo normas para la prevención y control de la contaminación del agua y su regulación federal o local (artículo 117, 120 y siguientes).

Se regula con detalle el denominado "Derecho a la información ambiental" en los artículos 159 bis y siguientes, a través del Sistema Nacional de Información Ambiental y de Recursos Naturales (SNIARN), a cargo de la SEMARNAT. Este Sistema tiene por objeto el registro, la organización, la actualización y la difusión de la información ambiental nacional y que se complemente con el Sistema de Cuentas Nacionales a cargo del INEGI, los cuales producen cada dos años un informe detallado de la situación nacional en esta materia, además de una Gaceta que publica los acuerdos legales e información de interés general, 
disponible al público a través de una simple solicitud por escrito, con obligación de responder en un plazo no mayor a veinte días y presunción en el sentido negativo en caso de falta de respuesta.

Por último, esta ley sufrió reformas el 19 de enero de 2018 en cuanto a los convenios de coordinación entre los diversos niveles de gobierno, la integración de un registro de emisiones y transferencia de contaminantes al aire, agua, suelo y subsuelo (artículo 109 bis) y la libertad de información ambiental en materia de agua, aire, suelo, flora, fauna y recursos naturales en general (artículo 159 bis 3).

\section{Ley Federal de Responsabilidad Ambiental}

El anterior presidente, Enrique Peña Nieto, expidió la Ley Federal de Responsabilidad Ambiental el 7 de junio de 2013, la cual consta de un total de 56 artículos. Algunas de las novedades más importantes de esta ley se refieren a los conceptos de "actividades altamente riesgosas", "criterio de equivalencia", "daño al ambiente", "daño indirecto", "cadena causal" y "estado base" (artículo 2).

Se integra un Sistema Nacional de Seguros de Riesgo Ambiental (artículo 8) y se establece taxativamente que "la responsabilidad por daños ocasionados al ambiente será subjetiva y nacerá de actos u omisiones ilícitos" (artículo 11). Se añade que estos daños patrimoniales y perjuicios se reclamarán en términos del Código Civil Federal.

Se considera de índole objetiva la responsabilidad ambiental cuando, los daños ocasionados al ambiente devengan directa o indirectamente de cualquier acción u omisión relacionada con materiales o residuos peligrosos; el uso u operación de embarcaciones en arrecifes de coral; la realización de las actividades consideradas como altamente riesgosas, y los previstos por el artículo 1913 del Código Civil Federal. (artículo 12)

Las sanciones económicas se establecen en un rango de trescientos a mil días de salario mínimo general vigente en la Ciudad de México (artículo 19) y se previene taxativamente la inexistencia de responsabilidad cuando el daño al ambiente tenga como causa exclusiva un caso fortuito o fuerza mayor (artículo 24).

Se concede acción pública para demandar la responsabilidad ambiental y el cumplimiento de las obligaciones, pagos y prestaciones en términos del artículo 27. La acción prescribe en doce años a partir de la fecha cierta de los daños producidos al ambiente y sus efectos (artículo 29).

Por otra parte, a nivel internacional el Consejo Económico y Social de la Organización de las Naciones Unidas (ONU) a través de su Comité de Derechos Económicos, Sociales y Culturales y bajo el rubro Observación General Número 15 (2002), plantea el fundamento jurídico del derecho al agua en los artículos 11 y 12 del Pacto Internacional de Derechos Económicos, Sociales y Culturales, establece las obligaciones de los estados partes (tanto las de carácter general como las de carácter específico y obligaciones básicas), las consecuencias de su violación y especialmente su aplicación en el plano nacional. 


\section{La figura del notario latino}

\section{Evolución histórica}

La institución notarial ha sido objeto de una larga evolución (Bono, 2019, pp. 39-42). Hay noticia cierta de la existencia de notarios o escribas desde el siglo XVIII a.C., inmortalizados en la famosa figura egipcia que se encuentra actualmente en el museo de El Cairo. Esta figura representa a un amanuense cómodamente sentado en posición de flor de loto exhibiendo sus instrumentos de trabajo, es decir, un rollo de papiro sostenido por la mano derecha en su regazo y un punzón de madera en su mano izquierda. Su actitud parece prestar una gran atención a lo que sucede a su alrededor y aparece expectante, atento a registrar inmediatamente lo que se le indique (Bono, 2019).

A partir de la referencia histórica documentada en esta escultura, tenemos también noticia de escribas en el siglo VII a.C. En efecto, Seva, Seraías, Jeremías y Nereías aparecen ejerciendo como escribas en Samuel (20:25 y 8:17) y Jeremías (36:2, 18, 23 y 32). En Grecia, en el siglo $V$ a.C., estos funcionarios eran conocidos bajo los nombres de mnemon, singraphos y promnemmon. En Roma, en el siglo III d.C., eran conocidos como tabellios.

Sin embargo, la consagración legislativa de las funciones de los amanuenses o escribas no tendría lugar sino hasta la expedición de las Constituciones XLV, XLVIII y LXXVI, expedidas por el emperador Justiniano en el siglo VI d.C., de las Capitulares en el año 803 por Carlomagno y de la Capitula, en los años 822-823, expedida por Lotario I.

No fue sino hasta el siglo XIII cuando, a la par de la consagración legislativa de las funciones de estos personajes, algunos expertos en esta ciencia dedicaron tratados especiales al desarrollo y naturaleza de la función. Ejemplo de ello son el Ars notariae (12241234) de Rainero de Perugia, el Ars notariae (1242-1254) de Salatiel, la Summa artis notariae (1492) de Rolandino Passegeri y la Practica artis notariatus (siglos XIII-XIV), de Petrus de Unzola, todos en lo que ahora se conoce modernamente como Italia.

Otros importantes desarrollos legislativos en España, tuvieron lugar en los años 1255 con el Fuero Real, en 1260 con el Espéculo, en 1263 con las Siete Partidas de Alfonso X, el Sabio, en 1304 con las Ordenanzas de Amiens de Felipe I, el Hermoso, en 1503, con la Pragmática de Alcalá, en 1512, con las Ordenanzas de Maximiliano y en 1539 con las Ordenanzas de Francisco I.

En el Nuevo Mundo también se desarrolló la función de estos personajes bajo el nombre de tlacuilos (siglo XV), aunque de manera algo más limitada, pues más que escribas, eran pintores -en este caso de códices-. En este material se representaban gráficamente escenas importantes de la vida de los pueblos prehispánicos.

También tenemos noticia cierta de que en 1492 acompañaba a Cristóbal Colón un escribano de naos, de nombre Rodrigo de Escobedo. En 1519 Diego de Godoy, a su vez escribano de Hernán Cortés, verificó el acta notarial de fundación de la Villa Rica de la Vera Cruz.

A principios del siglo XVII, en el año 1605, Nicolás de Yrolo Calar escribió el libro La Política de escripturas, y en el año 1792 tuvo lugar la fundación del Real Colegio de Escribanos de la Ciudad de México. 
A lo largo del siglo XIX y después de la expedición de la Ley Orgánica del Notariado de España en 1862, se dictó en 1864 el decreto que modificó el antiguo nombre de escribanos por el nombre actual de notarios públicos, la Ley Orgánica del Notariado y del Oficio de Escribano, expedida por Maximiliano de Habsburgo en 1865, la Ley Orgánica de Notarios y Actuarios del Distrito Federal (promulgada por Benito Juárez) y la Ley del Notariado (promulgada por Porfirio Díaz), que dieron lugar, con el paso del tiempo, a las modernas leyes del notariado del entonces Distrito Federal y ahora Ciudad de México $(2000,2018)$ y del estado de Veracruz (2015).

\section{El notario en la actualidad}

Actualmente el notario público mantiene una función privilegiada y exclusiva en el ejercicio de sus funciones, merced a su carácter de libre profesional del Derecho con reconocimiento público y social de la fuerza legal del Estado. El notario debe actuar con estricto apego a la legalidad aplicable al caso concreto, de manera imparcial, preventiva, voluntaria y auxiliar en la administración de justicia, todo ello respecto de asuntos en que no haya contienda. Esto hace del notario un verdadero consultor o consejero de cada parte, con atención personal y entrega cuidadosa.

De esta forma se cubren los requisitos de asesoría y consejo para cada una de las partes o solicitantes del servicio, sin descuidar los de la contraparte, ni ser parcial contra ella, sino ejerciendo hacia ambos la misma actitud, basada en lo "justo concreto" del caso. Así, la función notarial posee una naturaleza compleja, pues es pública en cuanto proviene de los poderes del Estado y de la ley, y es privada porque se desempeña por un profesional autónomo y libre, pues no está sujeto al Estado, ni jerárquicamente ni en cuanto a sueldo (artículo 26, LNCM).

El notario está obligado a conducirse en términos de profesionalidad, independencia, imparcialidad y autonomía, procurando la certeza y seguridad jurídicas que demanda la sociedad. No tiene más limitaciones que las previstas por la ley. Además, sus servicios son contratados bajo el principio general de libre elección del profesional. Así, vigila el interés de todas las partes y al propio tiempo cuida el orden jurídico. Su función, por tanto, es incompatible con toda relación de sumisión ante favores, poder o dinero que afecten su independencia, y es asimismo incompatible con toda restricción de la libertad personal.

Desde este punto de vista el notariado se ofrece por el Estado como una valiosa garantía institucional. El Estado establece las condiciones necesarias para el correcto ejercicio de la profesión en forma imparcial, calificada, colegiada y libre, en términos de ley. La imparcialidad del notario debe extenderse a todos los actos en los que intervenga.

Así, se salvaguardan los principios básicos de la ciencia notarial, que se hacen consistir en los siguientes: el de la conservación jurídica de fondo y forma del instrumento notarial y de su efecto adecuado; el de la conservación del instrumento notarial y de la matricidad en todo tiempo del mismo; el de la concepción del notariado como garantía institucional; el de la función profesional al servicio del bien y la paz y del respeto y el cumplimiento del derecho; el de estricto apego a la legalidad aplicable al caso concreto y el de cuidado del 
carácter de orden público de la función y su documentación en virtud del otorgamiento de la cualidad para dar fe, cedida por las autoridades.

\section{La función social del notario moderno}

Por todo ello los notarios son, como dice la ley, auxiliares valiosos en la administración de justicia (artículo 11, LNCM). En efecto, toda persona tiene derecho, en términos de esta ley, al servicio profesional del notario. Y por su parte, el notario está obligado a prestar sus servicios profesionales cuando para ello fuere requerido por las autoridades, por los particulares o cuando deba hacerse efectivo el cumplimiento de resoluciones judiciales, siempre y cuando, claro está, no exista impedimento legal. Asimismo el notario ejerce su función sin sometimiento al erario y sin sueldo o iguala del Gobierno o de entidades públicas o privadas, ni favoritismo alguno.

Los notarios tienen derecho a obtener de los propios clientes el pago de honorarios y de los gastos suficientes que se causen, de acuerdo con el arancel oficial que expida el Gobierno. Las autoridades podrán requerir de los notarios la prestación de sus servicios para atender asuntos de orden público o de interés social. En estos casos las autoridades y el Colegio convendrán los honorarios correspondientes. Los notarios participarán también, con tarifas reducidas y convenidas por el Colegio con las autoridades, en programas de fomento a la vivienda y regularización de la tenencia de la propiedad inmueble.

Casi todas las modernas leyes notariales conceden al notario la posibilidad de aceptar y desempeñar cargos académicos y docentes, de dirección de carrera o institución académica, de beneficencia pública o privada, de colaboración ciudadana y los que desempeñen gratuitamente a personas morales con fines no lucrativos. También pueden resolver consultas jurídicas y emitir dictámenes, o bien realizar actividades semejantes que no causen conflicto ni dependencia que afecten su dación de fe o asesoría imparcial y, por último, pueden ser árbitros o secretarios en juicios arbitrales, mediadores jurídicos y conciliadores.

La concesión de este tipo de facultades a los notarios públicos en nuestro país no es en ninguna manera novedosa. Existen precedentes eficazmente regulados de la intervención del notario en asuntos tales como el servicio electoral, donde este tipo de funcionarios están obligados a prestar sus servicios en los casos y en los términos que establezcan los ordenamientos electorales, con estricta obligación de que el servicio se preste de la mejor forma posible.

Asimismo, como lo he mencionado, los notarios participan también obligatoriamente en la ejecución de resoluciones judiciales y de programas especiales previstos por la ley (artículo 12, LNCM), programas de fomento a la vivienda y regularización de la tenencia de la propiedad inmueble (artículo 17, LNCM), procesamiento de sistemas estadísticos y cibernéticos (artículo 20, LNCM), atención a grupos sociales vulnerables, etcétera (artículo 23, LNCM).

La prestación de este tipo de funciones sociales por parte de los fedatarios mexicanos tiene siempre lugar bajo estrictas condiciones, sin carga al erario y sin sueldo o iguala de ningún tipo por parte de entidades públicas. En efecto, la regulación de los honorarios de 
este tipo de actividades se carga a los propios beneficiarios del servicio, de acuerdo con un riguroso arancel supervisado por las autoridades. Esta contraprestación se extiende desde luego al pago de los gastos que hayan de generarse por el trámite que genere la intervención notarial. El arancel debe ser forzosamente justo y proporcionado (artículo 15, LNCM).

\section{Los conflictos sobre el agua}

En general, una breve revisión de los problemas del recurso hídrico en nuestro país, según Heller (2017) debe incidir en los siguientes temas:

a. Las recomendaciones de las comisiones de derechos humanos resultan por lo general no cumplidas en la práctica;

b. La Agenda 2030 para el Desarrollo Sostenible impone obligaciones no siempre fáciles de cumplir;

c. No se ofrece información técnica precisa sobre la calidad del agua al consumidor;

d. En general, el agua de servicio público no es adecuada para su consumo doméstico;

e. Las estadísticas sobre agua potable y saneamiento suelen ser engañosas en cuanto a la calidad, la proporción, el destino, el acopio y el uso del agua;

f. En realidad, desde el punto de vista burocrático, el ejercicio de los recursos presupuestales recae en los municipios que suelen ser, de hecho la instancia más pobre de los tres niveles de gobierno,

g. Por último, es de destacar la notable despreocupación de algunos funcionarios de ciertos niveles de gobierno que han confesado en forma abierta que dado los índices de violencia en la actualidad, no resulta por ahora una prioridad el ocuparse de los problemas del agua y de su consumo. (2017)

Cada vez son más frecuentes los conflictos sobre el agua. Ejemplo de ello son los casos de Xochitepec Morelos (Aguilar, 2015) y de Jesús María de Aguascalientes (2016). Ellos son, en efecto, casos típicos de esta notable colisión entre el recurso hídrico y su cada vez más acuciante necesidad.

La mitad de las aguas en el país deben considerarse contaminadas en grado perjudicial para la salud humana. De hecho, apenas hace falta salir a una carretera o a una autopista para advertir que a un lado de las coloquiales denominaciones de "río seco", "arroyo estancado" o "estero del pantano", se encuentran grandes avenidas que fueron de agua algún tiempo o que ahora lo son solamente en la época de lluvias. Otros acuíferos están sobreexplotados en forma ineficiente.

De hecho, el reporte oficial de la ONU, a través del experto en derechos humanos al agua y al saneamiento Léo Heller, da cuenta de un panorama sumamente desalentador, que no avizora resultados favorables en el corto plazo (2017).

Y sin embargo, la Suprema Corte de Justicia de la Nación (SCJN) ha insistido particularmente en la necesidad de la suficiencia, salubridad, aceptabilidad y asequibilidad del recurso, a cargo de la Federación, de las entidades estatales y los municipios y precisando que se necesitan cincuenta a cien litros del recurso hídrico por día, por persona, 
para satisfacer apenas las necesidades más imperiosas, cuando solo otros cien litros se gastan en una ducha o en el lavado de trastes (Tesis 2a ${ }^{a}$. CXX/2003, p. 67).

Por otra parte, la legislación sobre la materia ha tenido que ser recientemente reformada, pues el Reglamento para la Prevención y Control de la Contaminación de Aguas es de 1973, la Ley General del Equilibrio Ecológico y la Protección al Ambiente es de 1988 (última reforma en 2018), la Ley de Aguas Nacionales es del año 1992 (última reforma en 2020), la Ley General de Bienes Nacionales, de 2004 (última reforma en 2018) y la Ley General de Asentamientos Humanos, de 2016 (última reforma en 2020). Ello sin contar que persisten todavía algunos obstáculos jurídicos importantes, como el hecho de que algunas instituciones no reconocen siquiera la naturaleza dual del derecho al agua y al saneamiento (elementos que no pueden concebirse en forma separada).

Otros esfuerzos a nivel internacional, asimismo importantes, se han hecho por ejemplo en el Foro Mundial del Agua (FMA), que se realiza cada tres años bajo el patrocinio del Consejo Mundial del Agua (CMA). De hecho, en marzo de 2018 se llevó a cabo el "8o Foro Mundial del Agua", en Brasilia.

Dos declaraciones importantes lograron obtenerse. Una, la denominada "Declaración de los ministerios públicos" y dos, la "Declaración de los jueces". Ambas declaraciones representan un esfuerzo relevante en la actitud más adecuada para la resolución del problema. La Conferencia de Jueces y Promotores contó con la participación de 83 especialistas provenientes de 57 países, que acotaron los objetivos de desarrollo sostenible en un valioso documento bajo el nombre "Diez principios fundamentales para promover la justicia hídrica a través de la aplicación de la legislación sobre el agua y el Estado de Derecho en materia ambiental" (2018).

Esta declaración de diez principios consta apenas de siete páginas donde se enuncian la necesidad de proteger a las mujeres, los niños, las personas mayores, las personas con discapacidad, los indígenas y otras minorías. Se reconoce además la necesidad de colaboración de los poderes del Estado, la sociedad civil y el sector privado aunque, por otra parte, el principio número uno destaca la prioridad del Estado en su manejo:

El Estado debería ejercer el manejo de todos los recursos hídricos y protegerlos en conjunto con sus funciones ecológicas asociadas, en beneficio de las generaciones presentes y futuras, así como de la comunidad de vida sobre la tierra.

Se establece la importancia del principio in dubio pro natura en unión de otros principios bajo los rubros "el que contamina paga", "el usuario paga", "la internalización de los costos", "las externalidades ambientales" y "la obligación propter rem" que se establece para usuarios y propietarios en forma vinculante y como obligación perdurable.

Una mención importante en este ámbito legislativo internacional se encuentra en el artículo 2.3 de la Convención de las Naciones Unidas sobre los Acuerdos de Transacción Internacionales Resultantes de la Mediación. Este novedoso acuerdo dice que se entenderá por mediación,

cualquiera sea la expresión utilizada o la razón por la que se haya entablado, un procedimiento mediante el cual las partes traten de llegar a un arreglo amistoso de su controversia con la asistencia de uno o más terceros (el mediador) que carezca de autoridad para imponerles una solución. (Art. 2.3) 
Por otra parte, esta Convención prohíbe los acuerdos de transacción a materias que se refieran a fines personales, familiares o domésticos; al Derecho de familia, al Derecho de sucesiones o al Derecho laboral, y a los acuerdos de transacción aprobados por órganos judiciales y que constituyan cosa juzgada.

\section{Las formas alternativas de justicia}

Las formas alternativas de justicia han recibido diversos nombres (negociación, conciliación, mediación, arbitraje, justicia alterna, acuerdos de mediación, amigable composición, acuerdo entre las partes, juntas de avenencia, concertación, etcétera).

Después de algunos momentos de vacilación, la doctrina jurídica ha decantado en mucho ya las principales diferencias entre los principales procedimientos de composición extrajudicial, es decir, la negociación, la mediación, la conciliación y el arbitraje.

a. Así, el primer nivel de este sistema de arreglos autocompositivos se refiere a la negociación, cuyo trámite es voluntario y no cuenta con una estructura formal. Su proceso es corto y el cumplimiento del laudo es voluntario.

b. El segundo nivel trata de la mediación, donde un tercero anima a las partes a negociar y a tratar de resolver sus diferencias sin mayor intervención en el fondo del asunto. Procura crear solamente un ambiente agradable de acercamiento para propiciar un arreglo, incluso desentendiéndose de los términos precisos del acuerdo, para luego intervenir al final en la formalización del mismo, si la negociación efectivamente funcionó. El tercero funge así, como un amigable componedor, quien suele invitar calurosamente a las partes a ponerse de acuerdo.

c. En cambio, el tercer nivel de estos acuerdos se refiere a la conciliación. El papel del conciliador es mucho más activo porque propone sugerencias de un arreglo para que sea libremente aceptado por las partes. Visto que este tercero imparcial no se encuentra involucrado emocionalmente en la discusión, es capaz de ver las cosas desde una perspectiva imparcial y razonable.

d. La cuarta forma de autocomposición de conflictos se refiere al arbitraje. En este caso, un tercero imparcial y profesionalmente preparado dirime la cuestión, una vez agotado el procedimiento formal de escucha de las partes, recepción de pruebas y emisión de laudo. Esta resolución cobra el valor de sentencia ejecutoria y el árbitro puede derivar su ejecución a un tribunal formalmente establecido.

Frecuentemente, la personalidad y el carácter del mediador y del conciliador ocasionan que estas dos instancias de solución se asemejen. Es distinto el caso del arbitraje, donde ya se ve que el procedimiento adopta un carácter mucho más formal, vinculante y ejecutivo.

He aquí un esquema didáctico (Pons y García, 2018; Cuadra Ramírez, s.f.), que establece la comparación entre estas cuatro distintas figuras jurídicas que suelen, en ocasiones, confundirse: 


\begin{tabular}{|l|l|l|l|}
\hline \multicolumn{1}{|c|}{ NEGOCIACIÓN } & \multicolumn{1}{|c|}{ MEDIACIÓN } & \multicolumn{1}{|c|}{ CONCILIACIÓN } & \multicolumn{1}{c|}{ ARBITRAJE } \\
\hline Es voluntaria & (Ídem) & Es obligatoria & Es voluntario \\
\hline $\begin{array}{l}\text { No tiene estructura } \\
\text { formal }\end{array}$ & (Ídem) & Sí tiene estructura formal & Es de estricto derecho \\
\hline $\begin{array}{l}\text { El impulso de las partes } \\
\text { es mayor }\end{array}$ & (Ídem) & $\begin{array}{l}\text { El impulso de las partes es } \\
\text { regular }\end{array}$ & $\begin{array}{l}\text { El impulso de las partes } \\
\text { es menor }\end{array}$ \\
\hline $\begin{array}{l}\text { No hay intervención de } \\
\text { terceros neutrales }\end{array}$ & $\begin{array}{l}\text { Al tercero neutral se le } \\
\text { denomina mediador }\end{array}$ & $\begin{array}{l}\text { Al tercero neutral se le } \\
\text { denomina conciliador }\end{array}$ & $\begin{array}{l}\text { Al tercero neutral se le } \\
\text { denomina árbitro }\end{array}$ \\
\hline $\begin{array}{l}\text { La duración del proceso } \\
\text { es corta }\end{array}$ & (Ídem) & $\begin{array}{l}\text { La duración del proceso es } \\
\text { corta }\end{array}$ & $\begin{array}{l}\text { Depende de los plazos } \\
\text { legales }\end{array}$ \\
\hline $\begin{array}{l}\text { El cumplimiento del } \\
\text { laudo es voluntario }\end{array}$ & (Ídem) & $\begin{array}{l}\text { El cumplimiento del laudo } \\
\text { es voluntario }\end{array}$ & $\begin{array}{l}\text { El compromiso arbitral } \\
\text { es obligatorio }\end{array}$ \\
\hline $\begin{array}{l}\text { La confidencialidad } \\
\text { atañe a las partes }\end{array}$ & (Ídem) & $\begin{array}{l}\text { La confidencialidad } \text { (hasta la acción de } \\
\text { absoluta }\end{array}$ \\
\hline $\begin{array}{l}\text { No hay remuneración } \\
\text { nuldad del fallo) }\end{array}$ & Sí hay remuneración & (Ídem) & (Ídem) \\
\hline $\begin{array}{l}\text { El negociador es elegido } \\
\text { por las partes o por un } \\
\text { tercero }\end{array}$ & (Ídem) & $\begin{array}{l}\text { El proceso es controlado } \\
\text { por el conciliador }\end{array}$ & $\begin{array}{l}\text { El proceso es controlado } \\
\text { por el árbitro }\end{array}$ \\
\hline $\begin{array}{l}\text { Produce solo una } \\
\text { "recomendación" }\end{array}$ & (Ídem) & El conciliador no decide \\
\hline $\begin{array}{l}\text { No sigue las reglas del } \\
\text { proceso }\end{array}$ & (Ídem) & El árbitro decide \\
\hline
\end{tabular}

Adaptado y actualizado de Pons y García, J. y Cuadra Ramírez, J.

En el arbitraje y en la amigable composición, el árbitro decide en conciencia y a buena fe guardada, en forma distinta al juicio arbitral de estricto derecho. El artículo 201 del RLAN establece el procedimiento, con términos improrrogables y con la producción de un laudo arbitral obligatorio.

\section{Fundamentación legal}

A nivel constitucional, el artículo 17 fue reformado en el año 2017, precisamente en su quinto párrafo, que ahora dice lo siguiente:

Las leyes preverán mecanismos alternativos de solución de controversias. En la materia penal regularán su aplicación, asegurarán la reparación del daño y establecerán los casos en los que se requerirá supervisión judicial.

Por su parte, el artículo 18 establece que "Solo por delito que merezca pena privativa de libertad habrá lugar a prisión preventiva. Las formas alternativas de justicia deberán observarse en la aplicación de este sistema, siempre que resulte procedente".

Aun la Ley de Comercio Exterior en su artículo 97 reza lo siguiente:

Cualquier parte interesada podrá optar por acudir a los mecanismos alternativos de solución de controversias en materia de prácticas desleales contenidos en tratados comerciales internacionales de los que México sea parte.

Con relación a la cuestión ambiental, la Ley Ambiental de la Ciudad de México del año 2004, previene lo siguiente: 
De conformidad con lo que establezca el reglamento de este ordenamiento, las autoridades ambientales podrán aplicar mecanismos alternativos para la solución de conflictos derivados de infracciones a las disposiciones jurídicas a que se refiere el artículo 201 del mismo. Dentro de dichos mecanismos, se podrán considerar la mediación, el arbitraje y la conciliación.

El arbitraje está previsto en el artículo 609 del Código de Procedimientos Civiles para la Ciudad de México. Dispone que las partes tienen el derecho de sujetar sus diferencias al juicio arbitral. Por su parte, el artículo 1051 del Código de Comercio precisa que "el procedimiento mercantil preferente a todos es el que libremente convengan las partes con las limitaciones que se señalan en este libro, pudiendo ser un procedimiento convencional ante Tribunales o un procedimiento arbitral".

La LAN se refiere a las atribuciones de la Comisión Nacional del Agua, quien puede conciliar y fungir, a petición de los usuarios, como árbitro en la prevención, mitigación y solución de conflictos relacionados con el agua y su gestión en términos del RLAN. Esta función también está dentro de la competencia de los Organismos de Cuenca, los cuales, en su caso, deben actuar a petición de los usuarios, de los Consejos de Cuenca, o de los estados (artículo 12 bis 6, XIV, LAN). Los CC colaborarán con las autoridades para dicha intervención (artículo 13 bis 3, XIX, LAN).

En la LAN se declaran de interés público la prevención, conciliación, arbitraje, mitigación y solución de conflictos en materia del agua y su gestión (artículo 7o bis, VI, LAN), como instrumentos básicos de la política hídrica nacional (artículo 14 bis 6, X, LAN).

Por su parte, los artículos 198 y siguientes del RLAN se refieren a la conciliación y al arbitraje específicamente en esta materia. El artículo 198 consigna pormenorizadamente el procedimiento a seguir:

I. La conciliación se iniciará a petición de parte interesada, presentando por duplicado la reclamación que se somete a conciliación y señalando nombre y domicilio de la parte a la que se le deberá correr traslado;

II. "La Comisión" señalará día, hora y lugar para la celebración de una audiencia de conciliación en la que se procurará avenir los intereses de las partes, la cual deberá tener lugar dentro de los quince días hábiles posteriores a la fecha de notificación de la reclamación respectiva;

III. "La Comisión" solicitará a las partes la información y documentación relacionada con los hechos, y las citará a la audiencia de conciliación, en el entendido de que si no comparecen, se hará un segundo citatorio y si tampoco lo hacen, se tendrá por concluido el procedimiento de conciliación, quedando a salvo los derechos de las partes;

IV. En caso de que el reclamante no comparezca a la audiencia de conciliación y no presente dentro de los siguientes quince días hábiles justificación fehaciente de su inasistencia, se tendrá por desistido de la reclamación y no podrá presentar otra ante "La Comisión" por los mismos hechos;

V. "La Comisión" expondrá a las partes un resumen de la reclamación y del informe presentado por ellas, señalando los elementos comunes y los puntos de controversia, y las exhortará para llegar a un arreglo, y sin prejuzgar sobre el conflicto planteado, les presentará una o varias opciones de solución; VI. "La Comisión" podrá en todo momento requerir a las partes los elementos de convicción que estime necesarios para la conciliación, así como para el ejercicio de las atribuciones que a "La Comisión" le confiere la ley. Las partes podrán aportar las pruebas que estimen necesarias para acreditar los elementos de la reclamación y de los informes; 
VII. "La Comisión" podrá suspender cuando lo estime pertinente o a instancia de ambas partes, la audiencia de conciliación hasta en dos ocasiones, casos en los cuales, el conciliador señalará día y hora para su reanudación, dentro de los quince días hábiles siguientes;

VIII. De toda audiencia se levantará el acta respectiva y los acuerdos de trámite que emita el conciliador no admitirán recurso alguno;

IX. Los convenios celebrados por las partes serán aprobados por "La Comisión" cuando no vayan en contra de la ley ni afecten a terceros; el acuerdo que los apruebe no admitirá recurso alguno;

$X$. En caso de no haber conciliación, "La Comisión" exhortará a las partes para que la designen como árbitro o designen a alguno de los árbitros que pueden actuar en su representación para solucionar el conflicto, cuyo listado la misma publicará, y

XI. En caso de no aceptarse el arbitraje, se dejarán a salvo los derechos de ambas partes.

\section{El notario como negociador, mediador, conciliador y árbitro}

Como ya dije, el notario puede intervenir como negociador, mediador, conciliador o árbitro en disputas de este tipo. La gran mayoría de las leyes notariales de las entidades federativas consigna en términos muy similares esta función, como en los casos de Aguascalientes (artículo 60), Baja California (artículo 11), Baja California Sur (artículo 20), Campeche (artículo 17), Chiapas (artículo 53), Chihuahua (artículo 4ㅇ), Coahuila (artículo 9ㅇ), Colima (artículo 7ㅇ), Ciudad de México (artículo 33), Durango (artículo 6으), Estado de México (artículo 5), Jalisco (artículos 3ํ y 37), Morelos (artículo 29), Nayarit (artículo 32), Nuevo León (artículo 80), Puebla (artículos 14 y 21), Quintana Roo (artículo 22), San Luis Potosí (artículo 8), Sinaloa (artículo 8ㅇ), Sonora (artículo 17), Tabasco (artículo 17), Tamaulipas (artículo 28), Tlaxcala (artículo 14), Veracruz (artículo 71), Yucatán (artículo 5으) y Zacatecas (artículo 44).

Las únicas entidades federativas que a la fecha no mencionan esta posibilidad de intervención en mediación y arbitraje son Guanajuato, Hidalgo, Michoacán, Oaxaca, Querétaro y Guerrero, es decir, un total de seis. No obstante, aunque no se consigne legislativamente esta posibilidad, queda claro que los notarios pueden desempeñar este tipo de función en la práctica, pues no hay obstáculo legal para ello.

En efecto, casi todas las entidades del país tienen leyes especiales de justicia alternativa o mediación, o de medios alternativos de solución de controversias. Así también, cada una de ellas menciona en artículos específicos la posibilidad de la mediación privada, aunque bajo un desempeño profesional:

Ley de Justicia Alternativa del Estado de Guanajuato, artículos 3, 6, 18 y 24.

Ley de Justicia Alternativa para el Estado de Hidalgo, artículos 3 y 4.

Ley de Justicia Alternativa y Restaurativa del Estado de Michoacán, artículo 2.

Ley de Mediación para el Estado de Oaxaca, artículos 2, 4 y 12.

Reglamento del Centro de Mediación del Poder Judicial del Estado de Querétaro, artículo 2.

El único caso que escapa a este esquema es el del estado de Guerrero, que hasta la fecha guarda el honor dudoso de no disponer de una ley específica.

Por tanto, en el marco legal de las funciones imparciales del notario, propongo que la intervención de este funcionario en los conflictos relacionados con disputas sobre el agua, 
con fundamento en la Constitución Política de los Estados Unidos Mexicanos, la Ley de Comercio Exterior, en las leyes notariales de la República Mexicana, en los códigos civiles, en los códigos de procedimientos civiles, en las leyes de justicia alternativa, en la Ley de Aguas Nacionales y en el Reglamento de la Ley de Aguas Nacionales.

La manera de proponer legalmente esta intervención del notario como negociador, mediador, conciliador o árbitro en conflictos del agua consiste únicamente en añadir una cláusula especial en los contratos relacionados. Según la propuesta de un contrato de compromiso arbitral, esta cláusula se reduce a lo siguiente:

Para la interpretación y cumplimiento del presente contrato, las partes se someten a la decisión de un árbitro. Los otorgantes nombran como árbitro al suscrito notario. En caso de que éste no acepte o sea recusable, el Colegio de Notarios de la Ciudad de México, nombrará de entre sus miembros, a un árbitro sustituto.

\section{Las ventajas de la intervención del notario}

Las ventajas que tiene la intervención del notario en la negociación, la mediación, la conciliación y el arbitraje en los diversos tipos de conflictos relacionados con el agua son múltiples. Las más importantes en términos de la Ley del Notariado de la Ciudad de México (2018) son los siguientes:

a. En cuanto a su autoridad:

- El notario es un funcionario público que ostenta el poder del Estado;

- Es uno de los funcionarios más representativos del estado de Derecho.

b. En cuanto a sus efectos:

- El notario es un depositario responsable de todos los archivos confiados a su cuidado;

- Como consecuencia de su actuación como negociador, mediador, conciliador o árbitro en conflictos del agua, el notario produce un documento público;

- Este documento público posee efectos probatorios contundentes;

- No admite dudas acerca de la resolución dictada o de las declaraciones vertidas por las partes;

- Dispone de la cualidad legal de su ejecución inmediata.

c. En cuanto a su responsabilidad:

- El notario es un funcionario rigurosamente vigilado por la autoridad gubernamental en el desempeño de su función, a través de auditorías que pueden tener lugar en cualquier tiempo;

- Como consecuencia de una eventual infracción, puede verse sometido a graves responsabilidades de tipo civil, administrativo, fiscal, penal y gremial.

d. En cuanto a su prestigio:

- La figura del notario público goza en México de un gran prestigio y reputación social que se remonta a la época colonial.

e. $\quad$ En cuanto a su infraestructura: 
- El notariado a nivel nacional dispone de oficinas convenientemente ubicadas en todo el territorio nacional;

- Tiene la capacidad para dar servicio eficiente tanto en las grandes urbes como en los municipios más pequeños;

- Las oficinas notariales guardan una presentación sumamente decorosa, moderna y eficiente;

- El notario dispone de recursos informáticos muy actualizados y sus oficinas disponen de aparatos modernos como teléfonos, computadoras, impresoras, fotocopiadoras y escáneres. El uso de la firma electrónica se está extendiendo cada vez más en los últimos años.

f. En cuanto a su costo:

- El notario es un funcionario privado, que no devenga sueldo del erario;

- El notario repercute sus costos directamente con los usuarios de sus servicios;

- Estos costos se reducen al mínimo indispensable para asegurar su intervención;

- El cobro de honorarios se encuentra rigurosamente vigilado por el Estado, mediante la expedición de un arancel periódicamente actualizado.

Por último, debe recordarse aquí, que en altas instancias internacionales, como en la Unión Internacional del Notariado, ha existido desde el año 1954 una gran preocupación por una intervención más profunda del notario público en las labores de negociación, mediación, conciliación y arbitraje.

Así, en distintos congresos se ha concluido lo siguiente:

III CONGRESO INTERNACIONAL DEL NOTARIADO, PARÍs, 1954

Tema: Responsabilidad notarial

Que si bien ciertos notarios tienen por misión exclusiva autenticar las convenciones de las partes, otros, en cambio, intervienen por ley en la elaboración de los contratos y desempeñan, asimismo, el papel de negociadores entre sus clientes.

Tema: función notarial-función social del notario

El notario desempeña un papel eminentemente social, ya sea como hacedor del instrumento notarial, o bien como consejero conciliador de las partes que ante él recurren.

IV CONGRESO INTERNACIONAL DEL NOTARIADO, RÍO DE JANEIRO, 1956

Tema: Organización del notariado

El notario latino tiene esencialmente un rol de conciliador, de árbitro entre las partes, rol éste que pertenece a la jurisdicción graciosa y voluntaria.

XXII CONGRESO INTERNACIONAL DEL NOTARIADO, BUENOS AIRES, 1998

Tema: Los derechos fundamentales del hombre y la misión del notario

Que para reducir el número y duración de los litigios corresponde que los estados recurran a la intervención preventiva y arbitral del notariado.

XX CONGRESO INTERNACIONAL DEL NOTARIADO, CARTAGENA DE INDIAS, 1992

Tema: La intervención del notario en el ámbito de la jurisdicción no contenciosa 


\section{Márquez J. / Intervención notarial en conflictos del Agua}

Que existe la preocupación, compartida por todos los representantes, de la necesidad de descongestionar las actividades y casos no jurisdiccionales a las oficinas de los juzgados y tribunales, para lograr uno de los bienes hoy en día más deseados en todos los países, como es la agilización de la justicia. (Pérez Fernández Del Castillo, 2001, pp. 3-61) 


\section{Bibliografía}

\section{Fuentes de consulta}

Aguilar, A. (23 marzo de 2015) México libra una dura guerra por el agua, Chicago Tribune. Recuperado de https://www.chicagotribune.com/hoy/ct-hoy-8437984-mexicolibra-una-dura-guerra-por-el-agua-story.html

Barragán Barragán, J. (2006). Concurrencia de facultades en materia de medio ambiente, entre la Federación y los estados, Temas selectos de Derecho ambiental, Ciudad de México.

Beck, U. (1988). Políticas ecológicas en la Edad del riesgo. Antídotos. La irresponsabilidad organizada, Barcelona.

Bono, J. (15 de mayo de 2019). Historia del Derecho Notarial Español, RNV, Revista Notarial de Veracruz, año 16, no. 35, pp. 39-42.

Cantú, M. y Garduño, H. (2006). Administración de derechos de agua, experiencias, asuntos relevantes y lineamientos. México, en: Derechos humanos, órgano informativo de la Comisión de Derechos Humanos del Estado de México, número 66, Estado de México.

Carmona Lara, M. C. y Ortíz Rendón, G. A. (2011). La constitución y el agua: apuntes para la gobernabilidad en el caso de agua en México y Evolución y perspectivas del marco jurídico del agua en México: nuevos retos y oportunidades para la gestión integrada del recurso hídrico, en: Agua, aspectos constitucionales, Rabasa, E. O. y Arriaga, C. B. (Coords.). Porrúa, Ciudad de México.

Cuadra Ramírez, J. G. (s.f). Medios alternativos de resolución de conflictos como solución complementaria de administración de justicia. Recuperado de https://www.scjn.gob.mx/sites/default/files/transparencia/documentos/becarios/ 040jose-guillermo-cuadra-ramirez.pdf.

Fernández, R. (2000). Gestión ambiental de ciudades, Teoría crítica y aportes metodológicos, PNUMA, Ciudad de México.

Gana Jesús María en la SCJN: cortará agua a morosos. (2 de diciembre de 2016). NEWSWEEK MÉXICO. Recuperado de https://newsweekespanol.com/2016/12/gana-jesusmaria-en-la-scjn-cortara-agua-a-morosos/ 
Heller, L. (12 de mayo de 2017). Declaración final sobre los derechos humanos al agua y al saneamiento, Organización de las Naciones Unidas, Ciudad de México. Recuperado de https://www.ohchr.org/SP/NewsEvents/Pages/DisplayNews.aspx?NewsID=21608\&LangID $=\mathrm{S}$

Jaquenod De Zsogon, S. (2002). Derecho ambiental, Madrid.

Juste Ruiz, J. (1999). Derecho internacional del medio ambiente, Madrid.

Ortíz Rendón, G. A. (2003). Memorias del Primer Encuentro Internacional de Derecho Ambiental, Ciudad de México.

Pérez Fernández Del Castillo, B. (2001). Doctrina Notarial Internacional, Porrúa, Ciudad de México.

Pons Y García, J. V. (1 de abril de 2018) "Resolución de conflictos en sede notarial”, en: RNV, Revista Notarial de Veracruz, año 15, no. 32.

Suprema Corte de Justicia de la Nación. (julio de 1973). Amparo en revisión 6236/55, La Perfeccionada, S.A., Semanario Judicial de la Federación, Séptima Época, vol. 26.

Suprema Corte de Justicia de la Nación. (enero-junio de 1988). Amparo en revisión 9526/84, Cartonaje Estrella, S.A. de C.V. y agraviados, Semanario Judicial de la Federación, Octava Época, t. I.

\section{Legisgrafía}

Brasilia Declaración de Jueces sobre justicia Hídrica (Declaración de 10 Principios). (21 de marzo de 2018). $8^{\circ}$ Foro Mundial del Agua, Brasilia, Brasil. Recuperado de https://www.iucn.org/sites/dev/files/content/documents/brasilia_declaracion_de jueces_sobre_justicia_hidrica_spanish_unofficial_translation_0.pdf

Código Civil Federal, 1929.

Código Federal de Procedimientos Civiles, 1943.

Constitución Política de los Estados Unidos Mexicanos, 1917.

Declaración de Estocolmo sobre el Medio Humano, 1972.

Declaración de Río sobre el Medio Ambiente y el Desarrollo, 1992. 
Ley de Aguas Nacionales, 1992.

Ley de Comercio Exterior, 1993.

Ley de Justicia Alternativa del Estado de Guanajuato, 2011.

Ley de Justicia Alternativa para el Estado de Hidalgo, 2009.

Ley de Justicia Alternativa y Restaurativa del Estado de Michoacán, 2014.

Ley de Mediación para el Estado de Oaxaca, 2004.

Ley Federal de Derechos, 1982.

Ley Federal de Responsabilidad Ambiental, 2013.

Ley General de Asentamientos Humanos, Ordenamiento Territorial y Desarrollo Urbano, 2016.

Ley General de Bienes Nacionales, 2004.

Ley General de Salud, 1984.

Ley General del Equilibrio Ecológico y Protección al Ambiente, 1988.

Ley de Ingresos de la Federación, 2019.

Ley del Notariado para la Ciudad de México, 2018.

Reglamento de la Ley de Aguas Nacionales, 1994.

Reglamento del Centro de Mediación del Poder Judicial del Estado de Querétaro, 2007.

Tesis 2a. CXX/2003. (octubre de 2003). Semanario Judicial de la Federación y su Gaceta, Novena Época, t. XVIII, p. 67. 